\title{
Computer Software Engineering Incubation and Skills Development for Job and Wealth Creation in Nigeria
}

\author{
Oluwole Charles Akinyokun*, Christopher Uwaje and Abejide Michael Adegoke \\ Department of Computer Science, Bells University of Technology, Nigeria
}

Submission: December 22, 2021; Published: January 26, 2022

*Corresponding author: Oluwole Charles Akinyokun, Department of Computer Science, Bells University of Technology, Nigeria

\begin{abstract}
The paper identified and evaluated the computer software industry as a potential source of job and wealth creation in Nigeria. The economy of Nigeria in the past decades has been analyzed and evaluated. The comparative study of software industry in India, Israel and Ireland is carried out and presented in some detail. The study of the software industry in Nigeria and its strengths, opportunities, weaknesses, and threats are carried out. It is concluded that Nigeria has the potentials to serve as software industry hub in Africa, thus creating software industry as an emerging source of job and wealth creation is imperative.
\end{abstract}

Keywords: Software; Web technology; Neuro computing technology; Stock markets

Abbreviation: ICT: Information and Communications Technology; SAP: Structural Adjustment Programme; VAT: Value Added Tax; NEEDS: National Economic Empowerment and Development Strategy; GSM: Global System for Mobile Communications; NSDTF: National Software Development Task Force; NSDI: National Software Development Initiatives; NCI: National Critical Infrastructure; NSPC: National Software Policy Committee; NSP: National Software Policy; NITDA: The National Information Technology Development Agency; GDP: Gross Domestic Product; CNII: Critical National Information Infrastructure

\section{Introduction}

Information and Communications Technology (ICT) is the world fastest growing technology in the world today. The hardware was the major driving force of the computer between 1940 and 1979 but things changed dramatically since 1980s when the major driving force of the computer is software. The development has changed the national resource-based economies to knowledge-based economies. Up till 1980, emphasis was on database processing, but today emphasis is on data mining and data warehousing. Knowledge engineering is replacing pure data and information-oriented engineering. The engine of ICT as a global agent for societal change in an emerging knowledge economy is the computer software. The computer software, which henceforth in this paper shall be referred to simply as software, is a tool for good governance, optimal productivity, transparency and accountability with a proven potential to contribute to national gross domestic product. Software development is the new shift in the history of human development with immense ability to bridge the economic gap between the developed and developing nations [1]. Many developing nations have today graduated into developed nations through software development, products and services.
The study of the strengths, weaknesses, opportunities, and threats of software industry in Nigeria shows that it has the potentials for the emergence as a global competitor in the software products, services and market with ancillary beneficial impact of poverty alleviation, gender equality, job, and wealth creation in Africa. There is evidence that the domestic market for software products and services is huge as exemplified by the increasing penetration of Internet connectivity, web technology, mobile phone usage, neuro-computing technology, development of national database, multi-modal biometric identification and authentication, knowledge discovery, data mining and data warehousing, emergency response systems, and a host of other platforms. The challenge facing Nigeria is how much of this market opportunity is linked to the emergence of a vibrant local software economy and capability as opposed to net negative capital flight, and job losses to international competitors. It is observed that while indigenous software is capable of reducing the existing capital flight through foreign software, it also has the capacity to attract tremendous foreign earnings desirable for accelerated growth of Nigerian economy and promote entrepreneurship for Nigerian youths. 


\section{Nigerian Economy in the Past Decades}

The income from indirect taxes and agricultural sector constituted the most important source of revenue in Nigeria between 1961 and 1971. At the beginning of the oil boom in the 1970 s, the contribution of indirect taxes to the revenue of the country fell from $58 \%$ in 1970 to $12 \%$ in 1980 . The oil boom caused a drastic fall in the contribution of agricultural sector to the national economy. The oil boom also brought about the attitude of Nigerians having preference for very high taste of goods and services. The middle-class income earners suddenly collapsed, thus leaving a wide gap between the poor and the rich in Nigerian society.

The global recession of the 1980s exposed the structural weakness of the petroleum-based economy of Nigeria. As the oil prices dropped, the economy found itself in the throes of chronic disequilibrium. The development compelled the Federal Government to resort into various policies calculated at moderating the deteriorating economic conditions. As part of the government Structural Adjustment Programme (SAP), a move was made to overhaul the system of indirect taxation with a view to making it more effective and efficient. The ultimate goal was to reduce taxation on income while increasing taxation on consumption of some goods and services. Moreover, there was the intention to reduce government over dependence on the volatile oil driven revenue. The Federal Government consequently introduced Sales Tax in 1986. The success story of the sales tax motivated the Federal Government to set up a study group on indirect taxation in 1991. The study group presented two reports with a strong recommendation for the introduction of Value Added Tax (VAT) to replace the existing Sales tax. The VAT was introduced in 1994 and it has made tremendous contributions to the national revenue since then and its impact has been felt in major areas of development in the country [2,3].

In [4], the National Economic Empowerment and Development Strategy (NEEDS) which is widely considered as Nigerian plan for prosperity is legislated as a national road map for economic empowerment and development. NEEDS focused on four key strategies, namely: re-orientating values, reducing poverty, creating wealth and generating employment. Basically, the major goal of NEEDS is the re-engineering of the growth process of Nigeria by exploring the means of diversifying the national product base away from petroleum products, services, and markets.

There was a re-occurrence of the global recession of petroleum products, services and markets in 2015 which exposed the structural weakness of the petroleum-based economy of Nigeria once again. The oil prices have continued to drop since 2015 and this development compelled the Federal Government to resort into various policies calculated at moderating the deteriorating economic conditions. The youths of the Nigerian society have capitalized on the development by setting up Yahoo business, social media business, Nollywood business and many terrorist activities which are windows to quite a lot of corrupt and criminal practices. The computer software which is one of the components of ICT is, currently, viewed as a critical element required for the global competitiveness of most industries and effective deployment of government services. In practice, the computer software has become a critical part of modern industrial infrastructure and a vehicle for implementing the other key elements of a knowledge economy. It is increasingly becoming a technology embodied in a vast and highly diversified range of products, services, and markets. In this paper, the strategic plan for software development as an emerging source of job and wealth creation in Nigeria is examined.

\section{Study of Software Industry in India, Israel and Ireland}

The growth and development of the computer industry was driven by hardware products, services, and markets between 1940 and 1980. Since 1980, the growth and development of the computer industry has continued to be driven by software products, services, and markets. In this Section, the comparative study of software industry in India, Israel and Ireland in some detail.

The desk study of the software industry in India, Israel and Ireland, which is classified as three I's identified three stages, namely: foundation stage, growth stage and consolidation stage of software industry:

a) During the foundation stage, India and Israel addressed specific ICT education to empower the people while Ireland addressed the empowerment of its software industry. Basically, the three countries concentrated their efforts on building skilled ICT and software workforce.

b) During the growth stage, Ireland started its indigenous software industry, India started its small clusters of special niche software businesses to cater for its growing domestic markets, while Israel established some high profiled software companies for global market. Basically, at this stage, the three countries established clusters of small business, targeted at niche markets, mostly situated around technology cities, villages or parks.

c) The consolidation phase saw the growth of the small clusters of software development firms into the global markets through linkage, collaboration and partnership with multinationals. A lot of advanced research and development work was common during this period which gave rise to the acquisition of advanced knowledge and skills in software engineering. This period saw the emergence of indigenous software firms from the three 'I's in international stock markets and revenues were in billions of USA Dollars.

While India took fifty years to consolidate its software industry, Israel and Ireland took forty years and thirty years 
respectively. The success story of these three countries can serve as a template for Nigeria in its bid to grow and develop its software industry. The strengths and opportunities of software industry in Nigeria that are highlighted below are primary indicators that Nigeria can achieve a greater height than India, Israel and Ireland within ten years. The success story of Global System for Mobile Communications (GSM) in Nigeria is an index for measuring the potential of Nigerian competitive edge in software markets in Africa and the world at large.

\section{Study of Software Industry in Nigeria}

There are two major schools of thought in the software industry in Nigeria as obtained in the developed world. It is presented in [5] that the first school of thought takes a study of software and uses the knowledge acquired to build softwarebased systems to enhance the performance of human experts in their problem domains. The second school of thought takes a study of the structure and function of the human being and uses the knowledge acquired to build human like intelligent software system. Today, software is applied in almost every field of human endeavor such as public administration, urban and regional planning, law and justice, environmental control, transportation, communications, health care and delivery, preparation of bible concordances and evangelism, crime investigation, security of life and property, and leisure activities. The current software development emphasizes the second school of thought in Nigeria.

In 2004, the National Software Development Task Force (NSDTF) was set up by the Federal Government while the National Software Development Initiatives (NSDI) was sponsored and organized by the private sector to provide a Road Map for software development in Nigeria. The 2005 recommendations of NSDTF and NSDI have not been backed up with any legislative and regulatory framework. It is imperative that Nigeria develops a software policy in order to align software as a National Critical Infrastructure (NCI) for national goals, aspirations and empowerment. The National Information Technology Development Agency (NITDA), in 2010, set up the National Software Policy Committee (NSPC) with members drawn from a broad spectrum of stakeholders to develop a National Software Policy (NSP) aimed at providing a blueprint to make Nigeria a competitive nation in software industry. The first author of this paper was the Chairman of the NSPC.

The vision of NSPC is: Innovative nation, creative minds connected and propelled by software capability. The missions of NSPC are:

a) Promoting software as one of the topmost Critical National Information Infrastructure (CNII) for the growth of Nigerian economy.

b) Promoting and facilitating software industry growth with a view to improving the quality and effectiveness of public service delivery, driving transparency and accountability in governance and increasing the contribution of software industry in the Gross Domestic Product (GDP) of Nigeria.

c) Improving the standard of living of the people of Nigeria through the use of software in all sectors as a tool to enhance productivity, efficiency and optimum utilization of resources.

d) Establishing National Software Infrastructure to cater for the needs of public administration, trade, commerce, industry, finance, entertainment, social media, education, culture, sports, tourism, peace, security and stability.

e) Promoting Nigeria as a software hub in Africa for the growth of software industry and facilitating the flow of investments.

f) Re-engineering or re-tooling the national human resources as workers for the emerging knowledge economy in Nigeria.

The global trends of the computer awareness, appreciation and use have been widely discussed in [6]. In Nigeria, the computers are viewed as general support resource for centralizing and integrating the operations of corporate organizations. Emphasis is on the computer model of quantitative variables of the operational data of organizations. In the developed world and some developing countries such as India, Ireland and Israel, the computers are viewed as strategic core resource in corporate organizations and emphasis is on the computer model of both quantitative and qualitative variables of the operational data of organizations.

The process of developing software in Nigeria over the years has not been adequately driven by the basic principles and practice of computer software engineering. The computer programming curriculum in Nigerian tertiary schools has, over the years, emphasized the science and engineering of computing with very little regard for the art of computing and its social, economic and political implications in Nigerian society. The software experts and professionals who are products of the technical oriented curriculum have often presented the computers as alternative to human experts rather than as a tool for enhancing the performance of human experts. In [7], it is argued that software is as an artificial life which is capable of been born, surviving and dying in an environment characterized by some stakeholders of diverse backgrounds. Thus, software is a subject of the vagaries of group dynamics, interactions, co-ordinations and communications. Therefore, the effective linkage, partnership and collaboration of the stakeholders of software development are desirable feature in the software industry.

The three programs presented in this paper for the strategic plan of software engineering incubation and skills development are:

a) Government shall deploy the political will and national 
resources with the support of the private sector to promote mass development of software human capital that is critical for job creation, entrepreneurship and the overall growth of the emerging knowledge economy.

b) Government shall promote the conceptualization, design, procurement, deployment, operation, monitoring, evaluation and maintenance/update of critical infrastructure to drive the software industry in line with global best practices and competitiveness.

c) Government shall recognize the Software Sector as a component of Critical National Information Infrastructure (CNII) deserving of pioneer status and shall promote incentives for software investors, developers and solution providers.

The objectives and strategic plan of the three programs were adequately documented and presented in [8].

\section{Strengths of software industry in Nigeria}

The population of Nigeria is about 240 million and the population of the youth who can kick start the software industry is about $60 \%$ of the 240 million. The youths have extremely strong entrepreneurial culture and drive. The schools in Nigeria are very many and some youths are sent abroad for primary, secondary and tertiary educations by their parents. The language of instruction in schools in Nigeria is English Language which gives the Nigerian youth a good advantage in software development. There are three level of government in Nigeria and at each level there is an impressive and commendable passion for enabling and sustainable software industry. There are many Nigerians that are home-based software experts and professionals and Nigerians in Diasporal who are software experts and professionals that are willing to collaborate with the public and private sectors on software development. The public and private sectors, in the past years, have been engaging themselves with the re-tooling or re-engineering their personnel. The public and private sectors are currently engaged in knowledge economy (e-government, e-business and e-payment). The three levels of government adopted the Millenium Development Goals as a strategy for job and wealth creation in the past decades. Many Nigerians are involved in software outsourcing which is considered as preparative ground for collaboration with some developing countries and multinational organizations in software development.

\section{Opportunities of software industry in Nigeria}

Beginning from the 1980, software has been acting as the driving force of the computers, thus there has been less emphasizes on hardware. It is relatively cheap to start a business in software industry and there is cheap labour in Nigeria which is an incentive for foreign and local investments that would use local labour. There is emergence of local demands for indigenous software services and products. There is the potentials of software developments as a source of job and wealth creation for the youth in Nigeria. There is emergence of Nigeria software products, services and markets that are capable of effective and efficient capability of competing in the global markets. There is an emerging cross cutting impact of software industry in other sectors of national economy. There is international interest in emerging economies, improvement of quality of life and poverty alleviation. There is the renewal of global focus on human capital development supported by multilateral funds and international development partners. Nigeria has the potential of serving as software industry hub in West Africa, Africa and the world at large.

\section{Weaknesses of software industry in Nigeria}

In Nigeria, there are no National Software Policy, Institutional Framework for Software Development and Intellectual Property Rights and Law Enforcement legislated and approved by the National Executive Council. The fiscal incentives for software inventors, developers and solution providers are poorly managed. There is absence of standards and quality assurance for software products and services. Software required by the public and private sectors is often procured from abroad with their attendant high cost of maintenance and very high capital flight. The training in Nigerian schools on computer programming emphasizes science and engineering. The trainers subsequently lay emphasizes on the computers as an artificial expert competing with the human experts rather than as end users aid to perform better. In many cases, end users are often scared and see computer as a potential threat to their job security. The home-based software experts and professionals who passed through the curriculum of the schools in programming have very limited emphasizes on social, political and economic aspects of data. In the absence of national Software Policy, the appropriate linkage, collaboration and partnership of experts and professionals with the public and private sectors are not handled properly. The coordination of many capacity building programs funded by the multinational bodies to provide basic software skills development are not supported at the public and private sectors. The public and private sectors neglect the abundant promotion programs that are desirable for the acquisition of domain specific knowledge and skills in software products, services and markets standardization. There is inadequate testing, measurement and certification of software experts and professionals. There is inadequate provision of basic data processing infrastructure, for example the performance of telecommunications and Internet Service Providers are epileptic.

\section{Threats of software industry in Nigeria}

There is inadequate continuity in initiatives such as policy formulation strategic plans and implementation procedure to nurture local software industry products, services and markets. The indigenous banking environment is characterized by a tendency towards high interest rate on loans and absence of venture capital. There are inadequate regulations on importation of software products and services by both public and private sectors of Nigerian economy. There is a culture of weak linkage between policy formulation and implementation through a lack 
of continuity in process and domain expertise. For example, the experts that are involved in developing a policy are often side tracked when the implementation of the policy comes to the round table for choosing the appropriate experts. This brings about the National attitude of excluding individuals or groups that contribute to policy formulation and strategic planning of a problem domain in implementation programs. Piracy and copyright infringement on intellectual property are not protected by law. There is protectionist policy in foreign software markets. Inherent vulnerability of emerging critical national information infrastructure already built largely on foreign software products and services.

\section{Conclusion}

The major resources of a country are man (human), money, method, materials (infrastructure) and time. The man uses money, method, materials, and time to achieve the aims and objectives of the country. The improper procurement, development and evaluation of the human resource have often led to the improper procurement and utilization of the other four resources and poor performance of the country. The rate of growth of the development of a nation depends, largely, on the quality of its human resource. Many countries in the world today are yet to develop, appropriately, because of the poor performance of their human resource in the management of the other resources. In the past decades, the economy of all nations has been largely driven by money. Today, there is knowledge economy which is anchored on ICT and ICT is today, largely, driven by software. In view of the abundant strengths and opportunities of Nigerian software industry, the establishment of Software Incubation Centers (SIC) in the six geo-political Zones of Nigeria is imperative for accelerated job and wealth creation for Nigerian Youths. The longevity of the attitudes of people towards ICT is indeed open to question, especially with the on-going evolution and revolution of Internet. The applications of ICT in the workplace and home are currently a subject of serious concern because of its likely effects on labour market and job security. In [9], it is expressed that if every instrument could do its own work, if the shuttle should weave of itself and the plectrum should play the harp unaided; then managers would not need workers and masters would not need servants. This is to say that ICT creates jobs whereby conventional staff have to be retrained, but a staff that fails to be retrained shall be made redundant and consequently obsolete.

Any successful new technology, in history, has always created its own set of applications that do not exist at the time it was conceived. For example, at the time electricity, telephone (communications device), automobile (transportation device) and the computer were invented, little did one knows that they could individually or jointly become essential to the way people live and work today. It is believed that a similar set generating process with considerable job opportunities and wealth creation will follow the introduction of a national policy on software development. Given the existing socio-economic status of Nigeria in the African continent, there is no doubt that the country has the potential for a global competition in the software market with a view to alleviating poverty in Nigerian society. A sizeable and demanding domestic market which can serve as a platform for developing software relevant skills, experience, user feedback on products, and services can be the springboard from which to launch into job and wealth creation. Moreover, a sizeable domestic market will draw large numbers of multinationals that are involved in software development into collaboration with local partners in order to serve that market. The major challenge for governments in its bid to develop the software sector is the provision of enabling and sustainable environment $[10,11]$.

There exist many policy documents for each sector policy plans of Nigerian economy, but the document for the implementation the plans are practically not available. In many cases, parties that were not involved in taking any initiatives and participating in the formulation of a policy plans were favored and invited to draw up implementation plan. This paper has identified software industry as an emerging source of job and wealth creation in Nigeria. Given the existing socio-economic status of Nigeria in the African continent, there is no doubt that the country has the potentials for a global competition in software industry. Among the success factors are economic strength and viability, high potential in human capital, existence of an entrepreneurial culture and drive and command of oral and written English language. It is believed that a lot can be gained in Nigeria in Information and Communications Technology (ICT) which drives the world's Knowledge Economy today. The success and sustainability of Nigerian future development is contingent on the mastery of National software vision. While commending the response and the constructive ICT interventions already put in place by successive Nigerian Governments, it is believed that the fundamental inclusion of software professional leadership, deployment of critical software infrastructure and building new frontiers constitute strategic imperatives for sustainable solutions to the perennial problems of national leadership, governance and developmental crisis across the length and breadth of Nigeria, in all the three tiers of Government. The above is derived from the basic principle that today, all successful Nations of the World are being governed by the innovative application of well-structured ICT. The professional concern and challenge are propelled by the fact that Nigeria currently lag far behind other Nations on digital e-readiness, with deficient consequences to nation building, development and survivability. This concern is further amplified by the fact that it is practically impossible to effectively govern 240 million Nigerians without strategically placing software experts close to the center of leadership, governance and national security. 


\section{References}

1. Akinyokun OC (2007) Harnessing the Potentials of Software Engineering for Poverty Alleviation in Nigeria. Invited paper in the Proceedings of e-Nigeria 2007 on Software Development and Applications in Nigerian Economy, ECOWAS Secretariat, Abuja, Nigeria.

2. Akinyokun OC (1993) Experimental Study of Value Added Tax (VAT) Database Administration, Invited Lecture in the Proceedings of the $23^{\text {rd }}$ Annual Conference of the Senior Staff of Federal Inland Revenue Service.

3. Akinyokun OC (1993) A Case for Modified Value Added Tax Information System (MVATIS). Invited Lecture in the Proceedings of Modified Value Added Tax Train the Trainers Course. Sponsored by the Federal Inland Revenue Service and organized by the Academic Planning Consultants.

4. NEEDS (2004) Meeting Everyone's Needs: National Economic Empowerment and Development Strategy. Publication of Nigerian National Planning Commission, Abuja.

5. Akinyokun OC (2002) Neuro-Fuzzy Expert System for Human Resource Performance Evaluation. First Bank of Nigeria Plc Endowment Fund Public Lecture, Federal University of Technology, Akure.
6. Akinyokun OC (1993) Survey of People Attitudes Towards Computer in Nigeria. Proceedings of the Second International Conference on Science and Technology in Third World Development, University of Strathclyde, Glasgow, Scotland.

7. Akinyokun OC (2000) Computer: A Partner to Human Experts. Twenty Third Inaugural Lecture of the Federal University of Technology, Akure, Nigeria.

8. NITDA (2012) National Software Policy. Publication of National Software Policy of Committee. National Information Technology Development Agency.

9. Schofield J (1985) The Guiding: Guide to Micro-computing. Basil Blackwell Publishers Limited, United Kingdom.

10. Akinyokun OC (1999) Assessment and Evaluation of the Utilization of Computing Facilities in the Public Sector of Nigeria. Invited contribution of a Chapter to the book titled "Nigerian Computer Society at 21 (COAN at 21)". A Publication of Nigerian Computer Society.

11. NSDTF (2005) Report of the National Software Development Task Force (NSDTF). Publication of the Federal Ministry of Science and Technology. Abuja, Nigeria.

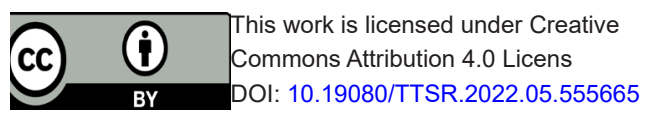

\section{Your next submission with Juniper Publishers will reach you the below assets}

- Quality Editorial service

- Swift Peer Review

- Reprints availability

- E-prints Service

- Manuscript Podcast for convenient understanding

- Global attainment for your research

- Manuscript accessibility in different formats

( Pdf, E-pub, Full Text, Audio)

- Unceasing customer service

Track the below URL for one-step submission https://juniperpublishers.com/online-submission.php 